\title{
Designing Interactive Storytelling: A Virtual Environment for Personal Experience Narratives
}

\author{
Ilda Ladeira ${ }^{1}$, Gary Marsden ${ }^{1}$, and Lesley Green ${ }^{2}$ \\ ${ }^{1}$ Department of Computer Science/ICT4D Lab, University of Cape Town \\ \{iladeira, gaz\}@ cs.uct.az.za \\ ${ }^{2}$ Department of Social Anthropology, University of Cape Town Lesley \\ green@uct.ac.za
}

\begin{abstract}
We describe an ongoing collaboration with the District Six Museum, in Cape Town, aimed at designing a storytelling prototype for preserving personal experience narratives. We detail the design of an interactive virtual environment (VE) which was inspired by a three month ethnography of real-life oral storytelling. The VE places the user as an audience member in a virtual group listening to two storytelling agents capable of two forms of interactivity: (1) User Questions: users can input (via typing) questions to the agent; and (2) Exchange Structures: the agent poses questions for users to answer. Preliminary results suggest an overall positive user experience, especially for exchange structures. User questions, however, appear to require improvement.
\end{abstract}

Keywords: Virtual Reality, Digital Storytelling, User Experience.

\section{Introduction}

Stories of personal experience are a compelling way to learn about historical events [1], particularly when told by those who lived the events first-hand. In South Africa, Apartheid enforced extreme racial segregation. Mixed-race neighborhood residents were relocated to areas allocated to their race and, typically, vacated neighborhoods were demolished to make way for new ones. "Forced removals" occurred throughout South Africa and District Six, in Cape Town, is a famous example [2, 3]. At the District Six Museum, visitors are able to hear this history told by two guides who once lived in District Six: Joe Schaffers and Noor Ebrahim. Sadly, the community of District Six ex-residents is now aging, leaving fewer people to tell of first-hand forced removal experiences. When Joe and Noor retire, museum visitors will no longer be able to hear their stories in person. Preserving stories such as theirs is the focus of many digital storytelling and cultural heritage projects $[4,5,6]$. Digital archives are not a matter of long-term preservation alone, but also of allowing wider dissemination of stories. However, little has been done to preserve real storytellers' dynamic and interactive qualities. Our work explores ways of presenting personal stories, beyond the, more typical, static video or 'talking head' presentations. We describe our multidisciplinary approach to creating a storytelling prototype informed by an ethnographic study of real-life oral storytelling. We propose two interaction techniques for making digital stories engaging by creating the illusion of interacting with real storytellers. 


\section{Background}

\subsection{Digital and Virtual Storytelling}

Digital storytelling typically seeks to preserve and disseminate real-life, non-fiction stories. Some have focused on supporting user generated content $[7,8]$ and others on creating publically accessible archives $[4,5,6]$. And, while some digital storytelling projects have provided interactivity in story creation and capture [7] and archive browsing [5], none, to the best of our knowledge, have explored interactive presentations of real-life stories. On the other hand, virtual storytelling projects have explored interactive storytelling extensively [9]. But, it has been, almost exclusively, with fictional content where users can manipulate, evolve or completely author narrative plots $[10,11,12]$. Others have also explored allowing users to influence stories' emotional tone, such as Silva et. al.'s system [13], where users could input how they would like the story told via tangible cards placed into an "influencing box". So, digital storytelling is devoted to presenting real-life stories whose plots listeners should, typically, not be able to edit, leading to story experiences with little or no interactivity. Meanwhile, virtual storytelling tends to give users agency over story plots, leading to highly interactive story experiences with little authorial control. We posit our work as something of an intersection, since we aimed to create digital, reallife stories where users can interact with story content, but not in ways that alter narrative plots.

\subsection{Simulated Museum Guides}

In museums, there have been impressive efforts towards digital tour guides which simulate specific guide-visitor interactions. After conducting a brief survey of tour guide experiences, Yii \& Aylett [14] created digital tour guides on hand-held devices. These mobile guides had different "personalities", which influenced the stories they told. Additionally users were able to continually input their level of interest which influenced the extensiveness of stories told. Yamazaki et al. [15] studied 15 instances of real guide-visitor interactions in an art museum to inform the creation of a robot capable of mimicking some of the interactions they observed. They placed special focus on the direction of a guide's gaze and their robot was able to detect human faces so as to direct its "gaze" in appropriate directions and able to respond to audience reactions and interruptions to a limited degree. The robot guide also periodically posed "involvement questions" where the robot would pose a question about a museum artifact, pause for a preset amount of time and then give the correct answer. However, responses to these questions were preset and, hence, non-interactive, serving rather to create the illusion of interaction. One of the interaction techniques in our storytelling prototype aims to improve on this by creating a more truly interactive form of involvement questions, which we term "exchange structures".

\subsection{Personal Experience Narratives}

Personal experience narratives are those where a storyteller tells of something that happened to themselves or an acquaintance [16]. Labov [17] describes a, now well- 
established, linguistic structure which personal experience narratives often follow wherein they are composed of a number of ordered components: abstract (signals a story's beginning); orientation (provides context); complicating action (the main event - usually something noteworthy or unexpected); resolution (the outcome); evaluation (commentary on why the story is interesting or noteworthy, this may appear near the end and throughout the story); and coda (signals the end). Martin and Plum [18] further identified distinct genres of personal experience narratives: recounts are exact descriptions of events akin to a courtroom testimony, exemplums serve to convey moral or pedagogical judgments and anecdotes convey emotional and/or humorous aspects of the teller's experience. With live oral storytelling, a storyteller conveys a story using words and body language and audiences may interact with the storyteller to influence a story's course or tone. Hence, each oral retelling of story differs with the extent of variation ranging from slight to where the audience might be considered as co-storytellers [19]. However, where a storyteller is telling a personal experience narrative, variations would not alter the overall plot. Discourse analyses of classroom conversations between teachers and students sheds light on the specificities of storyteller-audience interactions. A simple interaction might involve a student making a comment or asking a question to which the teacher responds. This can be extended to a longer interaction, called an exchange structure, which the teacher initiates by posing a question to which students may respond, leading to a dialog $[16,19,20]$. These exchanges are not unlike the "involvement questions" implemented in [15], but are, of course, interactive in that a teacher can respond to a number of different student answers. In our work, we used ideas of understanding personal experience narratives from [17] and [18] and insights on teacher-student interactions from [20] to analyze ethnographic data and design interactive storytelling agents.

\section{Research Overview}

As [10] points out, real storytellers establish a special connection with audiences that is difficult to emulate digitally. Our approach was to study real-life oral storytelling ethnographically in order to observe how experienced storytellers connect with audiences and draw them into their personal stories. To this end, we chose to observe Joe and Noor, who tell their personal stories every day to District Six Museum visitors. We aimed to learn about their techniques for making their personal stories engaging, dynamic and interactive. Our findings inspired the design and implementation of a storytelling prototype as a virtual environment (VE) containing interactive storytelling agents. Most recently, we conducted a large user study to evaluate our prototype's effectiveness.

\section{Ethnographic Study of Storytelling}

Our research began with the rather broad aim of observing real-life techniques for making narratives engaging, dynamic and interactive. We wanted to learn how oral storytellers make content vivid and compelling when telling about personal experience 
and examine real storyteller-audience interactions. The first author spent three months at the District Six Museum unobtrusively observing tours led by Joe, Noor, independent guides not employed by the museum, and, occasionally, other museum staff. We observed and took field notes for thirty-nine tours - of these we audio recorded (via lapel microphone) nine tours and video recorded snippets from a further four tours. Audio recorded tours ranged from nine to sixty minutes; these were transcribed and became a main focus of our analysis. Using the classification framework from Martin \& Plum [18], we identified anecdotes and exemplums which appeared most often in Joe and Noor's tours. This led us to five stories (two from Noor and three from Joe), for which we had recorded three to five retellings each. We used Labov's structural framework [17] to identify each retelling's constituent components, totaling nineteen distinct discourse analyses. This allowed us to discern a general linguistic structure for each of the five stories and examine the storyteller-audience interactions closely. We found that the stories matched the structure reported in [17] almost exactly and that they, somewhat disappointedly, did not vary much across retellings. Instead there was remarkable consistency in their structure and content. We believe this is due to the frequency with which Joe and Noor tell their stories - their storytelling has become well-rehearsed [21]. Despite this, their stories were not completely static and the variations we did observe arose, chiefly, due to two types of storyteller-audience interactions, which we translated into our prototype design.

First, audience questions: Audience members were free to ask questions at any point during a story. Typically, we noticed that they either waited for a pause in the storytelling or raised their hand and waited to be called on by the storyteller. Questions were also solicited by the storyteller explicitly inviting the audience to ask questions, usually at the end of a story. If no one asked questions immediately when invited, Noor especially, would drop hints for questions they could ask, for example: "You can ask me anything about District Six... games, gangsters, you name it, right?" Second, were exchange structures; an interaction initiated by the storytellers which matched the exchange structures defined in [20]. Periodically, a storyteller directed a question to the audience and then waited for responses. They were either looking for one or for a number of correct responses and the interaction would end when the audience gave enough correct answers. Storytellers usually handled incorrect answers by encouraging more answers. For instance, Noor often asked audiences to guess how he felt upon witnessing his home's demolition whereupon audiences offered responses, such as "sad", until reaching the answer Noor is looking for: "angry". In another example, he asks the audience to name some Cape Town townships, soliciting a number of correct answers before ending the interaction. An important observation about audience questions and exchange structures was that they always took place at the end of a narrative component and before the next began.

\section{Storytelling Prototype}

Our prototype design was based on the ethnography findings discussed in Section 4. We chose to implement a VE with interactive storyteller agents since we wanted a somewhat natural way for users to see the museum objects we were including and the 
likeness' of the Joe and Noor. However, the storytelling interactions we designed are orthogonal to a VE implementation and could be used in other storytelling applications. Fig. 1 shows the VE at the start: the user is part of a virtual audience facing two storytelling agents, modeled on Joe and Noor, and is able to move and look around using standard keyboard and mouse controls. The agents introduce themselves and, then, begin the first story, eventually telling five stories. A key design consideration in ensuring the prototype's sustainability was to make it possible for the museum to edit and improve on it easily. Thus, we chose a free implementation platform and ensured that it ran on an affordable desktop machine. We used Microsoft's XNA Game Studio and created the models in Blender 3D. The agents' animations were based on Joe and Noor's typical gestures and movements during storytelling. We noted these from video footage and had grown to know them well during the ethnographic study. The soundtrack was composed entirely of recordings gathered during the ethnography. While not our original intention, this allowed us to (a) present the stories as told spontaneously and (b) combine different retellings so that the VE presented, not one particular version of a story, but a composite version.

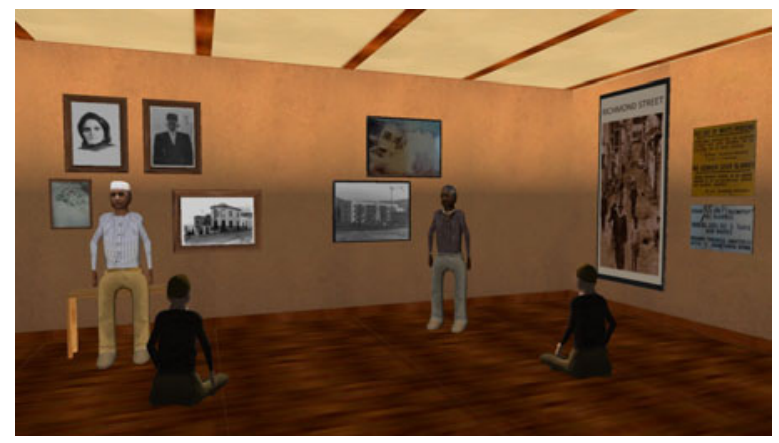

Fig. 1. The storytelling virtual environment including the storytelling agents modeled after Noor Ebrahim (left) and Joe Schaffers (right). Also visible, are other audience members and museum objects: around Noor are pictures of his grandparents, son and former home and near Joe, pictures of his former home, a former main street and Apartheid-era public signs.

\subsection{User Questions}

Here we aimed to mimic the hand raising behavior observed in the museum. So, at any point during a story, the user may press the Space bar to 'raise their hand' and signal the desire to ask a question. The prompt, shown in Fig. 2, "You may press SPACE to put up your hand", serves to remind users of this. When the user presses space bar, a hand icon, also shown in Fig. 2, is displayed to indicate that the user's hand is up. The agent first finishes the narrative component that is in progress before acknowledging the user's question. The typing window, shown in Fig. 3, then appears for the user to type their question. The agent has a reserve of possible question responses and we use simple keyword matching to find an appropriate response. If no matching response is found the agent responds by saying "I don't know". Occasionally the agent invites the user to ask questions by saying something like "If you have any questions, raise your hand", and then waits for the user to press Space. 
If the user does not do this within a certain timeframe, a virtual audience member asks a question instead. This way, the VE does not wait indefinitely, or unrealistically long, on the user. We also devised a way of supplying the user with question hints: If the user takes longer than a certain time to either type a question or 'raise their hand' when invited, the VE displays keywords hints for questions the agents can answer.
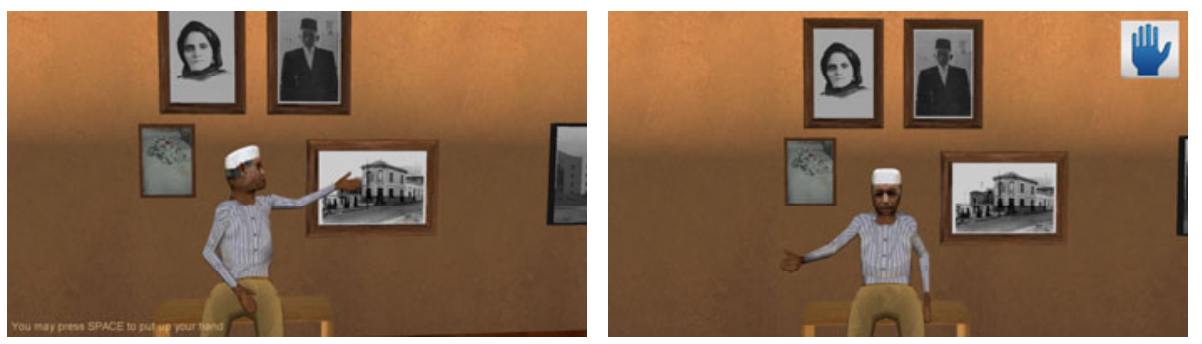

Fig. 2. While the Noor agent is telling a story the user is reminded that they may "put up their hand' by pressing the space key (left screenshot). When the space key is pressed, a hand icon, right, appears and is displayed until the agent acknowledges the user's question.

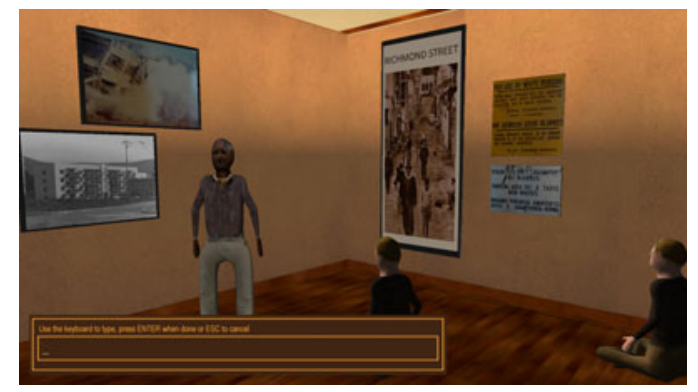

Fig. 3. The typing box in which users enter user question and exchange structure input

\subsection{Exchange Structures}

The second interaction type, exchange structures, is initiated by an agent directing a question to the user. When this happens, the typing box is, again, displayed for the user to type an answer. Each exchange structure has a 'final correct answer'; if the user enters this answer, the agent gives positive feedback and the interaction ends. The agent is also able to give feedback to a number of non-terminating answers (which may be correct or incorrect answers). As before, keyword matching is used to recognize the user's input. Whenever the user enters a non-terminating or unrecognized answer, the agent encourages another answer, saying something like "No, try again", and the typing box is again provided. To ensure that this interaction does not cycle indefinitely, the user has three tries at answering a question before a virtual audience member answers. Following on from the exchange structure described Section 4, we created an exchange structure initiated by the Noor agent asking "What do you think? How did I feel?"; if the user types "sad", he responds 
with "Sad" and waits for another answer; if the user types "angry", he responds "Angry! That's the word! I was so angry!" and the interaction ends. If the user types anything else, he responds "And what else?" and waits for another answer.

\section{Preliminary Results and Conclusion}

While it is impossible to simulate all the nuance and interactivity of a real storyteller, we believe our VE recreates two interactions common in oral storytelling. To test the effectiveness of adding user questions and exchange structures to a digital storytelling experience, we conducted a user evaluation with 150 university students. Participants signed up voluntarily, and were each paid 50ZAR. Each participant first experienced a training VE to practice keyboard and mouse navigation as well as user questions and exchange structures, which were presented textually. Participants then experienced the storytelling VE with an unobtrusive experimenter in the room making ad-hoc observations. Preliminary results indicate a surprisingly positive response with many participants reacting to the prototype by giggling, speaking, exclaiming and nodding. Many approached the experimenter afterward to find out more about the prototype. Participants' comments suggest particular enjoyment of the VE's storytelling nature and the exchange structures. However, user questions were less successful with numerous participants reporting frustration at the agents' inability to answer their questions. A superficial examination of usage logs revealed that a large proportion of the user questions were, indeed, unsuccessfully answered. Currently, the prototype is limited by the number of recordings we had of Joe and Noor answering questions. We have since recorded Joe and Noor answering all those questions which the agents were unable to answer. These will be added to the VE to increase the agents' repertoire of answers. The user questions could also be made more effective using artificial intelligence techniques more sophisticated than our simple keyword matching. The final step in this project is a deployment of our prototype as a trial exhibit at the District Six Museum, the original setting that inspired it. We have found that observing real-life storytelling there was an invaluable design starting point. Linguistics and discourse analysis helped us identify structure in the stories we recorded and well-defined interaction patterns, allowing us to ultimately produce a prototype that users responded to positively. This paper describes only the first part of our work; we look forward to conducting more in-depth analyses of our user evaluation and forthcoming museum deployment towards understanding which aspects of our design were truly effective and how it could be improved.

Acknowledgments. Our thanks to the District Six Museum, especially Joe Schaffers and Noor Ebrahim. Research partially supported by South Africa NRF Grant.

\section{References}

1. Maynes, M.J., Pierce, J.L., Laslett, B.: Telling Stories: The use of Personal Narrative in the Social Sciences and History. Cornell University Press, Ithica (2008)

2. Welsh, D.: The Rise and Fall of Apartheid: From Racial Domination to Majority Rule. Jonathan Ball Publishers, South Africa (2010) 
3. Ebrahim, N.: Noor's Story: My Life in District Six. IM Publishing, Charlesville (2009)

4. BBC, Capture Wales: Digital Storytelling, http: / /www.bbc.co.uk/wales/audiovideo/sites / galleries/pages / capturewales. shtml

5. USC Shoah Foundation Institute, Visual History Archive, http: //dornsife.usc.edu/vhi /

6. University of Cape Town, Centre for Popular Memory, http: / / www. popularmemory.org.za

7. Bidwell, N.J., Reitmaier, T., Marsden, G., Hansen, S.: Designing with Mobile Digital Storytelling in Rural Africa. In: 28th International Conference on Human Factors in Computing Systems (CHI), pp. 1593-1602. ACM Press, New York (2010)

8. Jones, M., Harwood, W., Buchanan, G., Frohlich, D., Rachovides, D., Lalmas, M., Frank, M.: Narrowcast yourself: Designing for Community Storytelling in a Rural Indian Context. In: 7th Conference on Designing Interactive Systems (DIS), pp. 369-378. ACM Press, New York (2008)

9. Cavazza, M., Pizzi, D.: Narratology for Interactive Storytelling: A Critical Introduction. In: Göbel, S., Malkewitz, R., Iurgel, I. (eds.) TIDSE 2006. LNCS, vol. 4326, pp. 72-83. Springer, Heidelberg (2006)

10. Brooks, K.M.: Do story agents use rocking chairs? In: ACM Multimedia 1996, pp. 317328. ACM Press, New York (1996)

11. Charles, F., Mead, S.J., Cavazza, M.: User Intervention in Virtual Interactive Storytelling. In: 1st Conference on Autonomous Agents and Multiagent Systems (AAMS), pp. 318325. ACM Press, New York (2002)

12. Mateas, M., Stern, A.: Structuring Content in the Façade Interactive Drama Architecture. In: 1st Annual Conference on Artificial Intelligence and Interactive Digital Entertainment (AIIDE), pp. 93-98. AAAI Press, Marina del Rey (2005)

13. Silva, A., Raimundo, G., Paiva, A.: Tell Me That Bit Again... Bringing Interactivity to a Virtual Storyteller. In: Balet, O., Subsol, G., Torguet, P. (eds.) ICVS 2003. LNCS, vol. 2897, pp. 146-154. Springer, Heidelberg (2003)

14. Yii Lim, M., Aylett, R.: Narrative Construction in a Mobile Tour Guide. In: Cavazza, M., Donikian, S. (eds.) ICVS-VirtStory 2007. LNCS, vol. 4871, pp. 51-62. Springer, Heidelberg (2007)

15. Yamazaki, K., Yamazaki, A., Okada, M., Kuno, Y., Kobayahsi, Y., Hoshi, Y., Pitsch, K., Luff, P., von Lehn, D., Heath, C.: Revealing Gauguin: Engaging Visitor's in Robot Guide's Explanation in a Art Museum. In: 28th International Conference on Human Factors in Computing Systems (CHI), pp. 1437-1446. ACM Press, New York (2010)

16. Pridham, F.: The Language of Conversation. Routledge, London (2001)

17. Labov, W.: The Transformation of Experience in Narrative Syntax. In: Labov, W. (ed.) Language in the Inner City: Studies in the Black English Vernacular. University of Philadelphia Press, Philadelphia (1972)

18. Martin, J.R., Plum, G.: Construing Experience: Some Story Genres. J. Narrative and Life History 7(1/4), 299-308 (1997)

19. Bauman, R.: Story performance and event: Contextual studies of oral narrative. In: Burke, R. (ed.) Cambridge Studies in Oral and Literate Culture. Cambridge University Press, London (1986)

20. Sinclair, J.McH., Coulthard, R.M.: Towards an Analysis of Discourse: The English used by teachers and pupils. Oxford University Press, Oxford (1975)

21. Ladeira, I., Nunez, D.: Story worlds and virtual environments: Learning from oral storytelling. In: 10th Annual Workshop on Presence, pp. 257-264. ISPR (2007) 